\title{
Doppler ultrasound imaging techniques for assessment of synovial inflammation
}

This article was published in the following Dove Press journal:

Reports in Medical Imaging

4 September 2013

Number of times this article has been viewed

\section{Emilio Filippucci' \\ Fausto Salaffi ${ }^{1}$ \\ Marina Carotti \\ Walter Grassi'}

'Rheumatology Department, Polytechnic University of the Marche, Ancona, Italy; ${ }^{2}$ Department of Radiology, Polytechnic University of the Marche, Ancona, Italy
Correspondence: Emilio Filippucci Rheumatology Department, Polytechnic University of the Marche, Ospedale "C Urbani", Via dei Colli 52, 60035 Jesi, Ancona, Italy Tel +39073|53 4I7|

$\mathrm{Fax}+390731534124$

Email emilio_filippucci@yahoo.it
Abstract: Ultrasound is an evolving technique, and the rapid progress made in ultrasound technology over the past ten years has dramatically increased its range of applications in rheumatology. One of the most exciting advances is the use of Doppler ultrasound imaging in the assessment of blood flow abnormalities at the synovial tissue level in patients with chronic inflammatory arthritis. This review describes the Doppler techniques available and their main applications in patients with inflammatory arthritis, discusses the evidence supporting their use, and outlines the latest advances in hardware and software. Spectral, color, and power Doppler allow sensitive assessment of vascular abnormalities at the synovial tissue level. Use of contrast agents enhances visualization of the small synovial vessels using color or power Doppler ultrasound and allows for accurate characterization of the rheumatoid pannus. Doppler techniques represent a unique method for assessment of synovial inflammation, showing blood flow characteristics in real time. They are safe, noninvasive, cost-effective, and have high sensitivity in revealing and monitoring synovitis. However, several questions still need to be answered. In the near future, the Doppler techniques described here, together with upcoming hardware and software facilities, will be investigated further and a consensus will be reached on their feasibility and appropriate use in daily rheumatologic practice.

Keywords: power and color Doppler techniques, ultrasound, contrast media, synovitis, rheumatoid arthritis

\section{Introduction}

Synovial angiogenesis is a characteristic feature of chronic inflammatory arthritis, and is considered an important factor in the chronicity of the disease ${ }^{1}$ and the best predictive marker of joint damage. ${ }^{2}$ The presence of hypervascularized synovial tissue correlates with disease activity, and appears to be crucial for the destructive behavior of the rheumatoid pannus. ${ }^{3-7}$ Rheumatologists have always been interested in methods providing information on synovial inflammation, including imaging techniques.

Ultrasound is an evolving technique and the rapid progress in ultrasound technology over the past ten years has dramatically increased its range of applications in rheumatology. One of the most exciting is the use of Doppler ultrasound imaging for assessment of abnormalities in blood flow at the synovial tissue level in patients with chronic inflammatory arthritis. ${ }^{8-13}$ This review describes the Doppler techniques available and their main applications in patients with inflammatory arthritis, discusses the evidence supporting their use, and outlines the latest advances in the relevant hardware and software. 


\section{Doppler techniques in assessment of synovial inflammation}

Doppler techniques rely on the Doppler effect, ie, a change in the frequency of ultrasound waves when they reflect from moving objects, such as red blood cells. Spectral, color, and power Doppler allow sensitive assessment of vascular abnormalities at the synovial tissue level. Further information can be obtained when color or power Doppler ultrasound is enhanced by administration of an intravenous microbubble contrast agent. ${ }^{14,15}$

The main reasons for using Doppler ultrasound to assess the vascularity of synovial tissue are to distinguish between active and inactive synovitis, to assess disease activity at the joint level, and to predict persistent arthritis, flare of disease, and progression of joint damage. ${ }^{16-20}$ Recent advances in ultrasound hardware and software are likely to impact the use of Doppler techniques in daily rheumatologic practice in the near future. High-frequency linear volumetric probes allow for a rapid operator-independent acquisition process, and high-definition Doppler imaging together with dedicated software counting colored pixels facilitates the interpretation of color and power Doppler findings. ${ }^{21-23}$

\section{Spectral Doppler}

Spectral Doppler allows for detailed analysis of blood flow in a single vessel, tracing its velocity-time curve and showing systole and diastole during each cardiac cycle. Several measurements can be obtained, and automatic calculation of the resistive index (RI) can be used to assess synovial inflammation. In the cerebral and renal arteries, high diastolic flow is normal because low peripheral resistance is essential for continuous high perfusion. Conversely, normal blood flow in musculoskeletal tissues is characterized by high resistance. An increment in diastolic velocity and a reduction in RI result from abnormal perfusion and permeability of the vessels due to synovial inflammation and angiogenesis. ${ }^{24}$

Cutoff RI values for distinguishing between normal blood flow and pathologic perfusion have been investigated in a number of studies. Terslev et al reported a mean RI of 0.8 at the wrist and metacarpophalangeal joints in healthy subjects, which was higher than the values in the range of 0.4-0.76 reported in the literature for patients with rheumatoid disease. ${ }^{25}$ More recently, Carotti et al ${ }^{26}$ found a significant difference between mean RI at the wrist and finger joints in patients with rheumatoid disease and healthy subjects ( 0.72 versus 0.86 , respectively). Using 0.79 as the cutoff RI value, the sensitivity and specificity of this technique for distinguishing inflamed joints from healthy ones was $89.6 \%$ and $78.8 \%$, respectively. Significantly higher RI values were found in patients with early rheumatoid arthritis than in those with long-standing disease. ${ }^{26}$ Another common application of spectral Doppler is to confirm the presence of blood flow in areas where color and/or power Doppler signals are visualized.

\section{Color Doppler}

Color Doppler ultrasound generates a real-time map of colored pixels in the grayscale setting, showing sites of blood flow in the area of interest defined by the Doppler box. Color Doppler ultrasound allows measurement of blood flow velocity, and the color of the signal indicates the direction of blood flow, with red spots generated by blood flow directed toward the probe and blue ones away from it. No signal is displayed if the direction of blood flow is perpendicular to the ultrasound beam. A number of studies have shown the ability of color Doppler to detect synovial vascularization in patients with chronic inflammatory arthritis, to differentiate between normal and abnormal blood flow and between inactive and active pannus, and to assess changes in synovial blood flow induced by different treatments. ${ }^{26-28}$

Color Doppler findings indicative of synovial vascularization can be found at the wrist and metacarpophalangeal joints in healthy subjects. ${ }^{25,26}$ Terslev et al scanned 324 joints in 27 healthy subjects, and found color Doppler signals in 15 of 27 wrists, 17 of 27 first carpometacarpal joints, 10 of 135 metacarpophalangeal joints, and 1 of 135 proximal interphalangeal joints. ${ }^{25}$ Hence, given that detection of intraarticular color Doppler signals cannot be considered a sign of inflammation, differentiation between normal and pathologic intra-articular perfusion should be based on qualitative findings, and normal ranges should be calculated for Doppler findings if quantitative methods are to be used.

Different methods have been proposed for scoring intraarticular color Doppler signals. ${ }^{29}$ The two main methods are the semiquantitative scoring system, which assesses the amount of color Doppler signals using a four-point grading scale, and the quantitative scoring system, which counts color pixels in synovial tissue using dedicated post-processing software. The semiquantitative method allows for more rapid assessment, and relies on the skills and experience of the sonographer, whereas the quantitative method has the potential to be more reproducible, but requires more time. In a recent study, Terslev et al compared these two methods when scoring at the wrists of 46 rheumatoid patients in the dorsal view. A high correlation and comparable inter-reader agreement was found between these scoring systems. ${ }^{30}$ 


\section{Power Doppler}

Power Doppler encodes the amplitude of the Doppler signal resulting from the volume of blood present, and enables sensitive assessment of low velocity flow in small vessels of the synovial tissue. Even when using last-generation ultrasound equipment, there is no substantial difference between color and power Doppler with regard to detection of slow flow, ${ }^{31}$ and the majority of studies investigating the role of ultrasound in patients with chronic inflammatory arthritis have been performed using power Doppler. Several studies have evaluated the validity of power Doppler in the assessment of synovitis in patients with rheumatoid arthritis. Concurrent validity has been investigated using clinical examination, histology, and dynamic magnetic resonance imaging (MRI) as the gold standard assessment technique, ${ }^{8,32}$ and predictive validity has been assessed using the rate of relapse flares and progression of joint damage as outcome measures. Power Doppler was found to be useful in the evaluation of disease activity in rheumatoid patients ${ }^{8,27,28}$ and for monitoring the response to treatment. ${ }^{33-37}$ Moreover, in patients with rheumatoid arthritis in clinical remission, the presence of a power Doppler signal at the wrist and metacarpophalangeal joints was found to be predictive of progression of joint damage (Figure 1). Therefore, its use in the clinical setting of remission may reveal active vascularized synovium and therefore influence therapeutic decision-making.

\section{Contrast-enhanced color/power Doppler}

An ultrasound contrast agent consists of a suspension of relatively uniform, highly reflective, stabilized gas-filled spheres, which enhance the Doppler signal, increasing its sensitivity for detection of low velocity blood flow at the level of the small vessels. Ultrasound contrast agents have been found to be helpful mainly in non-musculoskeletal imaging, but also at the synovial tissue level in patients with rheumatoid arthritis using power and color Doppler. ${ }^{14,15,38}$ Use of contrast agents enhances visualization of the small synovial vessels by color or power Doppler ultrasound, and enables accurate characterization of the rheumatoid pannus, which may be hypervascular, hypovascular, or avascular. ${ }^{14,15,39}$

In 2005, the International Arthritis Contrast Ultrasound group undertook a multicenter study comparing contrastenhanced ultrasound versus grayscale and power Doppler ultrasound for detection of joint vascularity in patients with rheumatoid disease. Contrast-enhanced ultrasound was found to be helpful for differentiating between active synovitis and inactive intra-articular thickening, and for
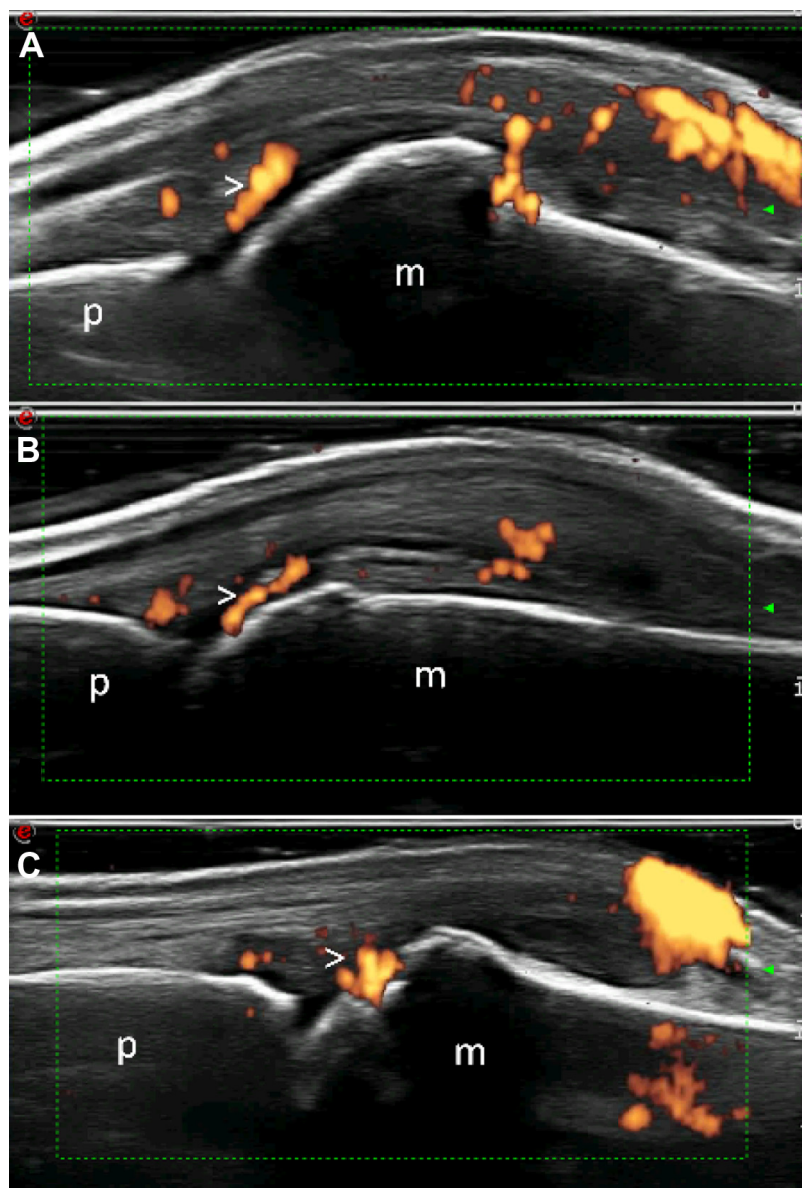

Figure I Rheumatoid arthritis. Power Doppler ultrasound images of metacarpophalangeal joints acquired on dorsal longitudinal scan. (A) Hyperemic inflamed synovial tissue (arrowhead). (B) Cartilage damage due to active rheumatoid pannus invasion (arrowhead). (C) Subchondral hot erosion (arrowhead). Abbreviations: $m$, metacarpal bone; $p$, proximal phalanx.

improving measurement of the thickness of inflamed synovial tissue. ${ }^{40}$

Analysis of time-intensity curves in a region of interest allows quantification of synovial inflammation. The area under the curve, the slope of the ascending and descending curve, measurement of flow rate, assessment of vascular volume, and estimate of mean velocity are all aspects allowing detailed evaluation of synovial inflammation.

A number of studies have investigated contrast-enhanced power and/or color Doppler ultrasound in the assessment of synovitis. Most of these have been performed in patients with rheumatoid arthritis and showed that contrast agents amplify detection of the color signal and facilitate differentiation between active and inactive synovitis ${ }^{15,41}$ (Figure 2).

Studies comparing contrast-enhanced power Doppler and MRI in the evaluation of synovitis have yielded inconsistent results. ${ }^{39,42,43}$ An important aspect to bear in mind is that there is a limited window of opportunity for performing 


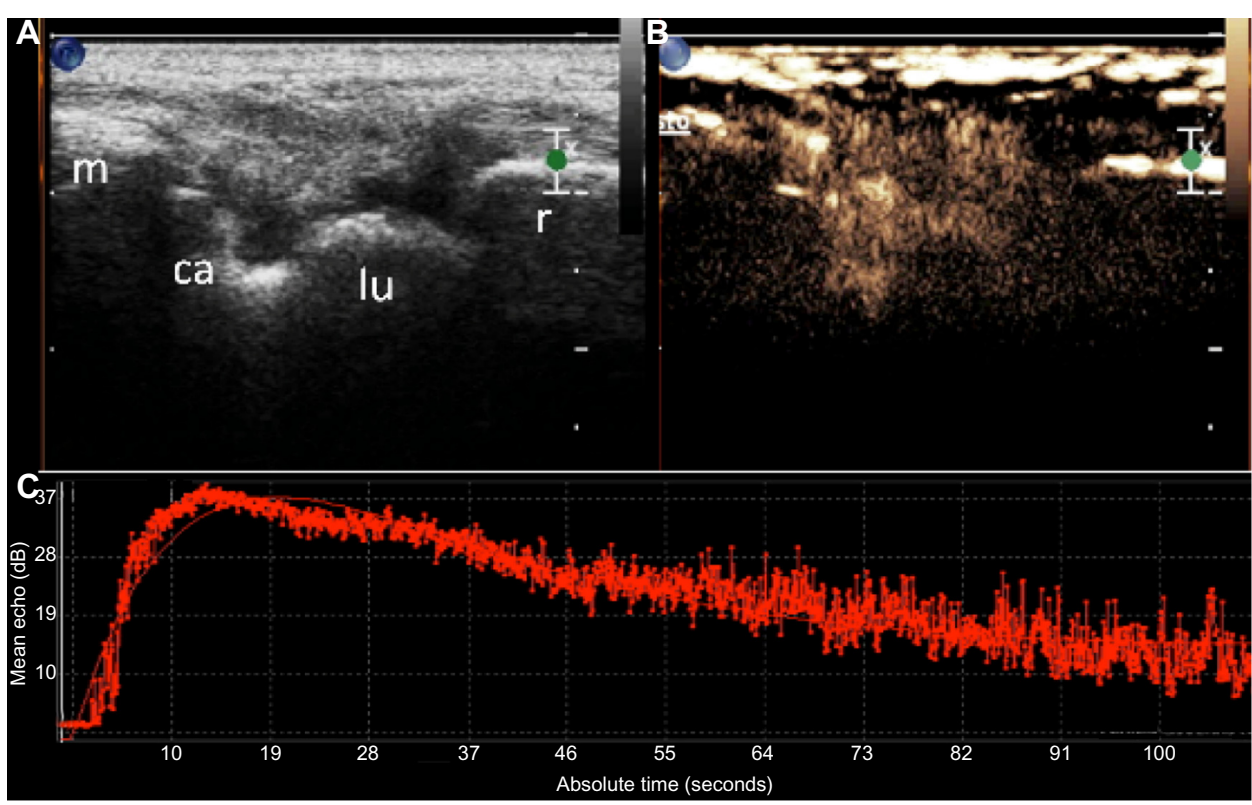

Figure 2 Rheumatoid arthritis. (A) Dorsal longitudinal scan of the wrist showing moderate joint cavity widening mainly due to an increased amount of synovial hypertrophy. (B) After intravenous injection of an ultrasound contrast agent (SonoVue), multiple intra-articular microbubbles, representing the degree of vascularity of the synovial membrane due to joint inflammation, could be detected. (C) The corresponding contrast enhancement curve after administration of SonoVue.

Abbreviations: $r$, radius; lu, lunate bone; ca, capitate bone; $m$, third metacarpal bone.

a contrast-enhanced power Doppler ultrasound examination with Levovist because of rapid destruction of microbubbles with a high mechanical index, resulting in a decrease in signal intensity with time. ${ }^{44}$ The mean molecular diameter of Levovist is about $3 \mu \mathrm{m},{ }^{45}$ and no extravasation into the surrounding tissues is found, indicating that Levovist acts as an intravascular contrast agent. Contrast-enhanced MRI can provide information not only on vascular perfusion but also on permeability. ${ }^{46-48}$ In fact, the MRI contrast agent, gadolinium-diethylenetriamine pentaacetic acid, can extravasate easily. ${ }^{49}$

There is evidence showing that administration of a contrast agent significantly improves the detection of color and power Doppler signals at the knee and finger joints in patients with rheumatoid arthritis. ${ }^{15,50}$ An increment in the number of joints showing a color Doppler signal was also found in healthy subjects using two different contrast agents (Levovist and SonoVue). ${ }^{51}$ However, Szkudlarek et al reported that contrast-enhanced power Doppler ultrasound did not increase sensitivity in the detection of synovitis at the metacarpophalangeal joints in six patients with rheumatoid arthritis; in patients who did not show precontrast power Doppler findings, no power Doppler signals were found after administration of the ultrasound contrast agent. ${ }^{43}$

The conflicting results obtained in studies investigating the sensitivity of contrast-enhanced power or color Doppler can be explained by several factors, including quality of the ultrasound equipment, the limited number of ultrasound examinations performed, the image acquisition technique, the joint scanned, and the nature of joint disease. The main issues limiting the use of ultrasound contrast media are the relatively high running costs involved, the relatively short duration of examination, and the need for optimally designed bubbles for near-field investigation at higher frequencies.

\section{Quality of Doppler findings}

There are several technical aspects to consider when carrying out a careful and reliable Doppler examination of synovial tissue. First, the patient must be positioned comfortably so as not to increase pressure at the anatomic site under examination. A standard neutral position avoids an increase in intraarticular pressure and consequent false-negative Doppler findings due to reduced blood flow. ${ }^{52,53}$ Moreover, a low skin temperature has been found to reduce the amount of color Doppler activity in the synovial tissue of rheumatoid patients, so cooling of the hands should be avoided before Doppler assessment. However, heating does not affect color Doppler findings. ${ }^{54}$ Second, an adequate amount of gel should be used to ensure minimal compression of the vessels. Third, there is evidence suggesting that power Doppler activity at the metacarpophalangeal joint level shows diurnal variation in 
rheumatoid patients with active disease, being higher in the morning and lower in the afternoon. ${ }^{55}$ Fourth, changes in treatment affect Doppler findings indicative of synovitis or tenosynovitis. ${ }^{33-37,56}$ Finally, the Doppler parameters should be set in order to obtain maximal sensitivity for detection of abnormal blood flow. Torp-Pedersen and Terslev have addressed this issue by publishing recommendations for ultrasound machine settings. ${ }^{31}$

\section{Newer Doppler techniques}

Very high-frequency probes operating at a B-mode frequency higher than $15 \mathrm{MHz}$ may reach a Doppler frequency higher than $11 \mathrm{MHz}$. These recently available transducers allow for highly sensitive detection of abnormal blood flow in the synovial tissue of the small joints of the hands and feet and in the superficial tendons surrounded by synovial sheaths. However, such a high Doppler frequency may yield false-positive findings due to detection of normal feeding vessels in the small joints of the bony extremities. The shape of the Doppler signal, typically linear in longitudinal view, and the topography are helpful features for identifying feeding vessels (Figure 3). Moreover, a Doppler frequency higher than $11 \mathrm{MHz}$ enables detection of blood flow in very superficial targets, including the extensor tendons of the finger (Figure 4), skin, and nails, opening up new avenues of research. ${ }^{57}$
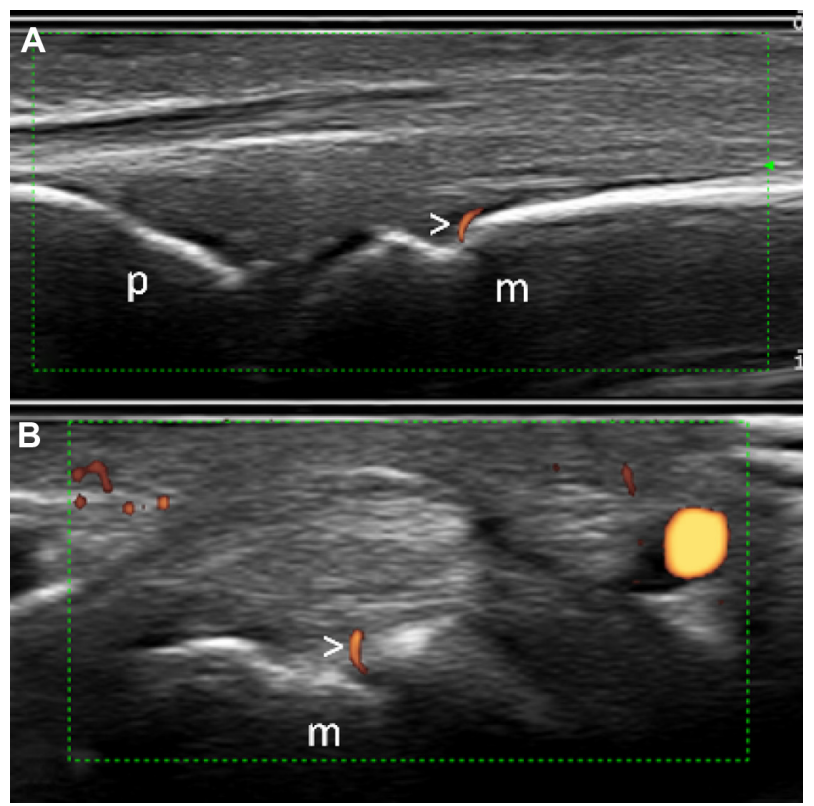

Figure 3 Healthy subject. Second metacarpophalangeal joint. Dorsal longitudinal (A) and transverse (B) scans showing a feeding vessel appearing as a colored line (arrowheads) in both views.

Abbreviations: $\mathrm{m}$, metacarpal bone; p, proximal phalanx.

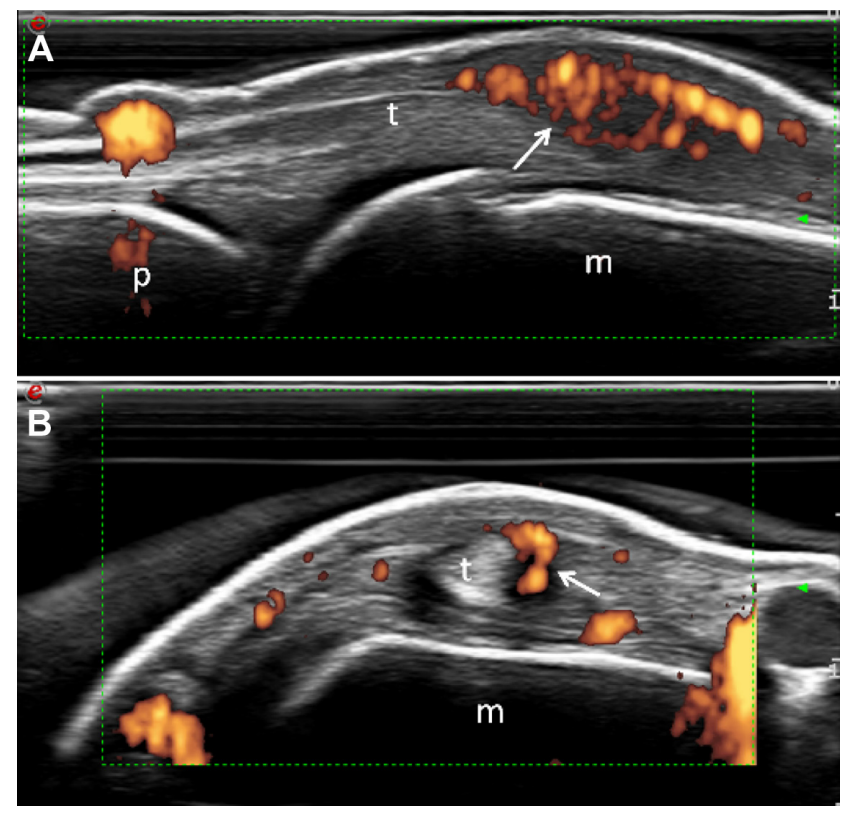

Figure 4 Psoriatic arthritis. Power Doppler images of a third metacarpophalangeal joint. Dorsal longitudinal (A) and transverse (B) scans showing active inflammation (arrows) surrounding the finger extensor tendon ( $t$ ) in both views.

Abbreviations: $m$, metacarpal bone; $p$, proximal phalanx.

High-frequency three-dimensional ultrasound technology allows for sensitive, rapid, and less operator-dependent acquisition of Doppler images from the small joints in patients with chronic inflammatory arthritis. Using volumetric probes, acquisition of three-dimensional data sets is automatic because the system stores all the ultrasound images under the probe footprint while the ultrasound beam is moved electronically at a constant velocity. The color or power Doppler ultrasound images acquired are then available for analysis using dedicated software which allows for three-dimensional image reconstruction and composition of a mosaic using tomographic ultrasound imaging (Figure 5). The main limitations of three-dimensional ultrasound using volumetric probes include lower sensitivity compared with conventional ultrasound using last-generation high-frequency probes, the inability to use real-time scanning maneuvers, and the fixed maximal size of the 3D data set, which is adequate for the small joints of the hands and feet but cannot include a large joint like the knee.

High-definition color or power Doppler allows for refinement of the software displaying the Doppler signal. The same Doppler shifts are seen after a digital process proportionally reduces the number of colored pixels and avoids the overflowing signal covering the underlying grayscale images. Sensitivity is preserved and interpretation of the topographic distribution of the power Doppler signal is made easier (Figure 6). 

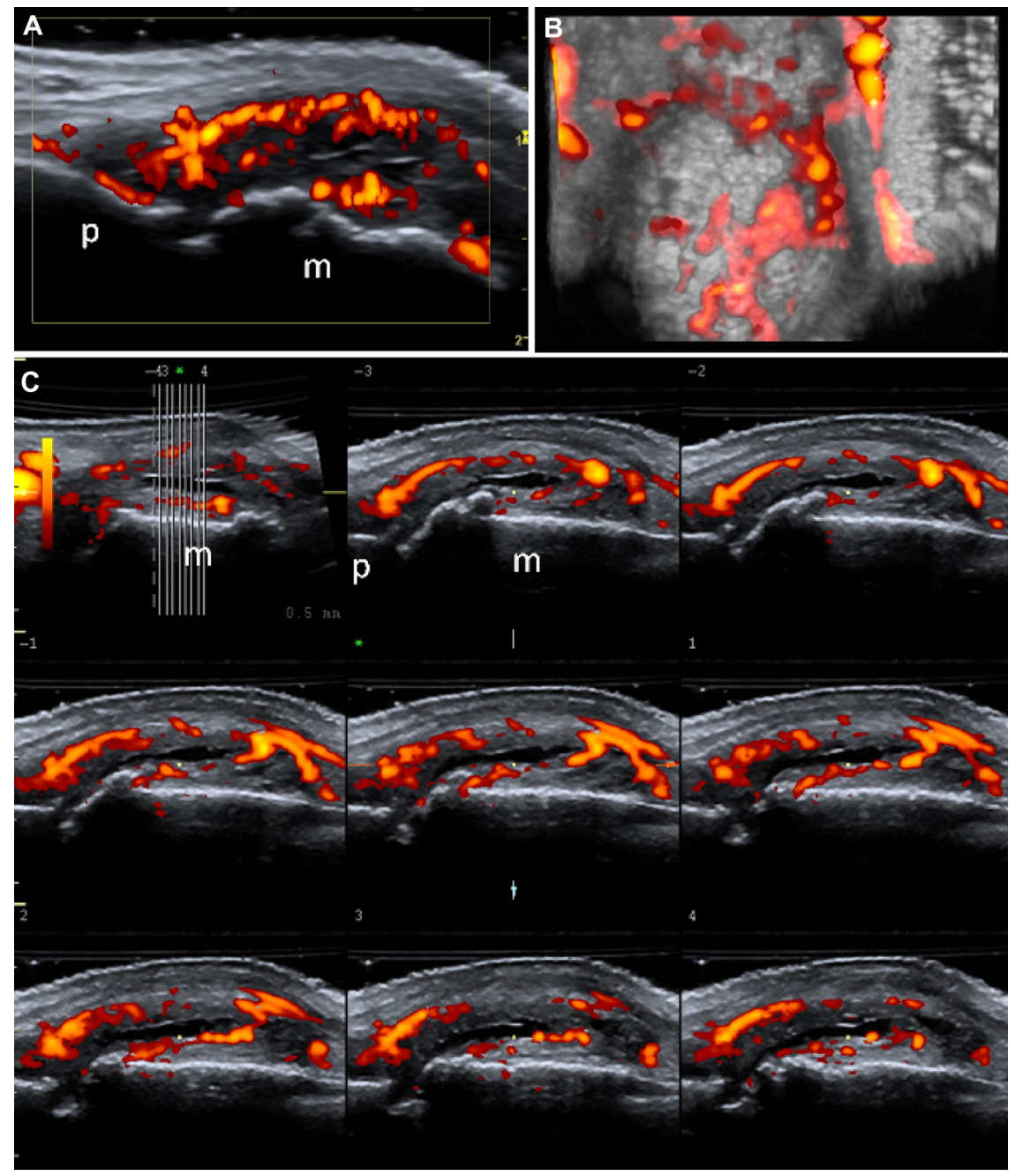

Figure 5 Rheumatoid arthritis. Power Doppler images of a second metacarpophalangeal joint. (A) Conventional two-dimensional ultrasound image acquired on a dorsal longitudinal scan. (B) Corresponding three-dimensional view. (C) Mosaic of pictures automatically displayed by tomographic ultrasound imaging software showing images obtained on adjacent scanning planes, $0.5 \mathrm{~mm}$ away from each other.

Abbreviations: $\mathrm{m}$, metacarpal bone; $\mathrm{p}$, proximal phalanx.
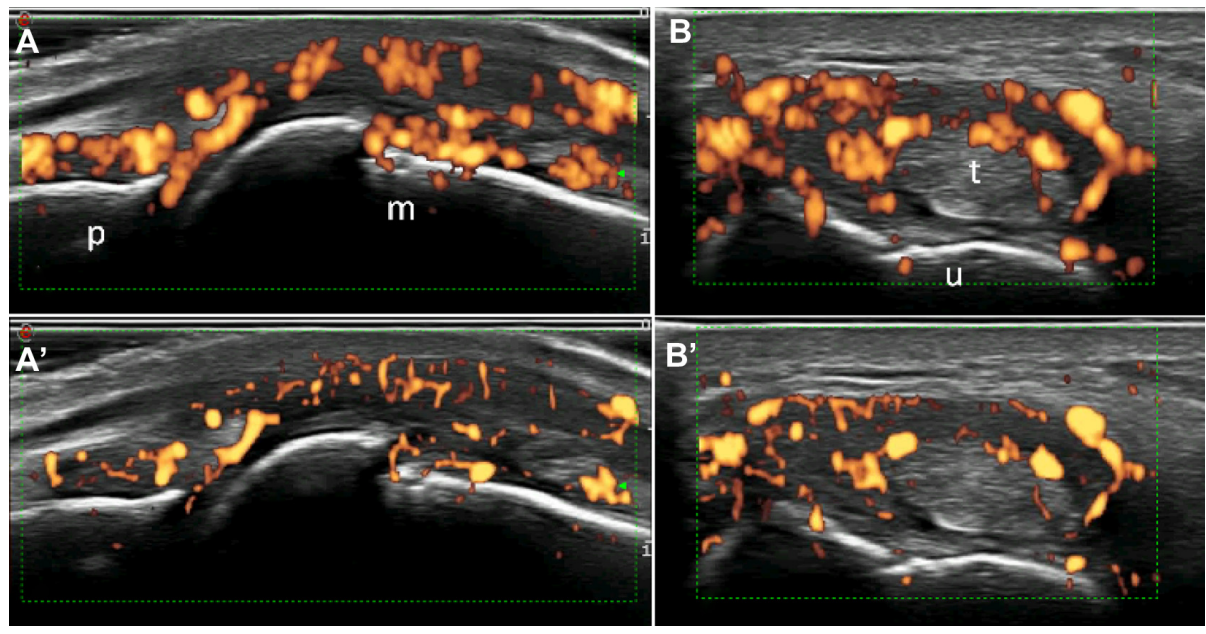

Figure 6 Rheumatoid arthritis. Power Doppler images of a third metacarpophalangeal joint in the dorsal longitudinal view (A) and extensor ulnaris carpi tendon ( $\mathrm{t}$ ) on transverse view (B) showing active synovitis and tenosynovitis, respectively. Images obtained using a Doppler frequency of II.I MHz. (A'-B') Corresponding images acquired using a high-definition technique showing the same degree of inflammation with thinner power Doppler signals.

Abbreviations: $\mathrm{m}$, metacarpal bone; $\mathrm{p}$, proximal phalanx; u, ulna. 
Table I Research agenda for Doppler imaging in joint disease

- Consensus should be reached on the best scanning protocol and scoring system, which should be defined in order to solve specific clinical questions in patients with chronic synovitis using the currently available Doppler techniques

- Identification of the reasons for intraobserver, interobserver, and machine variability and agreement with reference methods assessing synovial inflammation

- Determination of Doppler values predicting subsequent progression of joint damage and short-term or long-term relapse

- Evaluation of the value of Doppler ultrasound in the diagnosis of rheumatoid arthritis in patients with early undifferentiated disease, using long-term follow-up as the gold standard assessment technique

- Determination of the sensitivity of Doppler ultrasound measures to change and comparison of therapy-induced changes showing the smallest detectable difference

- Identification of the best core set of joints to scan in order to achieve the best compromise between feasibility and comprehensiveness

- Continuous development and validation of the latest Doppler ultrasound technical devices (ie, volumetric probes, transducers with a Doppler frequency higher than $14 \mathrm{MHz}$ ) for assessment of synovial inflammation

- Promotion of educational and training programs to encourage use of Doppler techniques amongst rheumatologists.

\section{Summary}

Doppler techniques enable sensitive detection of vascular abnormalities at the synovial tissue level in patients with chronic inflammatory arthritis. The quality of Doppler findings depends not only on the skills and experience of the sonographer, but also on the hardware and software of the ultrasound machine. The main applications of Doppler ultrasound in the assessment of synovial tissue vascularity are to distinguish between active and inactive synovitis and to assess disease activity at the joint level, as well as to predict persistent arthritis, flare of disease, and progression of joint damage. Spectral Doppler allows for detailed analysis of blood flow in a single vessel, tracing its velocity-time curve and showing systole and diastole in each cardiac cycle. Use of a contrast agent enhances the signal-to-noise ratio and may improve nondiagnostic Doppler examination by raising the intensity of weak signals to a detectable level.

\section{Conclusion}

Doppler techniques are a unique method for assessing synovial inflammation, showing blood flow characteristics in real time. They are safe, noninvasive, have low running costs, and can reveal and monitor synovitis in a highly sensitive manner. However, several questions need to be answered. Table 1 highlights the main issues that need to be addressed by investigators committed to this field of research. The Doppler techniques described in this review, together with upcoming hardware and software facilities, will be further investigated in the near future, and a consensus will be reached on their feasibility and appropriate use in daily rheumatologic practice.

\section{Disclosure}

The authors report no conflicts of interest in this work.

\section{References}

1. Weber AJ, De Bandt M. Angiogenesis: general mechanisms and implications for rheumatoid arthritis. Joint Bone Spine. 2000;67:366-383.

2. Walsh DA. Angiogenesis and arthritis. Rheumatology. 1999;38: $103-112$.

3. FitzGerald O, Bresnihan B. Synovial membrane cellularity and vascularity. Ann Rheum Dis. 1995;54:511-515.

4. Zvaifler NJ, Firestein GS. Pannus and pannocytes. Alternative models of joint destruction in rheumatoid arthritis. Arthritis Rheum. 1994;37: 783-789.

5. Conaghan PG, O'Connor P, McGonagle D, et al. Elucidation of the relationship between synovitis and bone damage. A randomized magnetic resonance imaging study of individual joints in patients with early rheumatoid arthritis. Arthritis Rheum. 2003;48:64-71.

6. Ballara S, Taylor PC, Reusch P, et al. Raised serum vascular endothelial growth factor levels are associated with destructive change in inflammatory arthritis. Arthritis Rheum. 2001;44:2055-2064.

7. Taylor PC. VEGF and imaging of vessels in rheumatoid arthritis. Arthritis Res. 2002;4:S99-S107.

8. Naredo E, Bonilla G, Gamero F, et al. Assessment of inflammatory activity in rheumatoid arthritis: a comparative study of clinical evaluation with grey scale and power Doppler ultrasonography. Ann Rheum Dis. 2005;64:375-381.

9. Salaffi F, Filippucci E, Carotti M, et al. Inter-observer agreement of standard joint counts in early rheumatoid arthritis: a comparison with grey scale ultrasonography - a preliminary study. Rheumatology. 2008;47:54-58.

10. Filippucci E, Iagnocco A, Salaffi F, Cerioni A, Varesini G, Grassi W. Power Doppler sonography monitoring of synovial perfusion at wrist joints in rheumatoid patients treated with adalimumab. Ann Rheum Dis. 2006;65:1433-1437.

11. Salaffi F, Carotti M, Manganelli P, Filippucci E, Giuseppetti GM, Grassi W. Contrast-enhanced power Doppler sonography of knee synovitis in rheumatoid arthritis: assessment of therapeutic response. Clin Rheumatol. 2004;23:285-290.

12. Szkudlarek M, Court-Payen M, Strandberg C, Karlund M, Klausen T, Østergaard M. Power Doppler ultrasonography for assessment of synovitis in the metacarpophalangeal joints of patients with rheumatoid arthritis. Arthritis Rheum. 2001;44:2018-2023.

13. Terslev L, Torp-Pedersen S, Savnik A, et al. Doppler ultrasound and magnetic resonance imaging of synovial inflammation of the hand in rheumatoid arthritis. Arthritis Rheum. 2003;48:2434-2441.

14. Carotti M, Salaffi F, Manganelli P, Salera D, Simonetti B, Grassi W. Power Doppler sonography in the assessment of synovial tissue of the knee joint in rheumatoid arthritis: a preliminary experience. Ann Rheum Dis. 2002;61:877-882.

15. Klauser A, Frauscher F, Schirmer M, et al. The value of contrast enhanced color Doppler ultrasound in the detection of vascularization of finger joints in patients with rheumatoid arthritis. Arthritis Rheum. 2002;46:647-653.

16. Freeston JE, Wakefield RJ, Conaghan PG, Hensor EM, Stewart SP, Emery P. A diagnostic algorithm for persistence of very early inflammatory arthritis: the utility of power Doppler ultrasound when added to conventional assessment tools. Ann Rheum Dis. 2010;69: 417-419. 
17. Filer A, de Pablo P, Allen G, et al. Utility of ultrasound joint counts in the prediction of rheumatoid arthritis in patients with very early synovitis. Ann Rheum Dis. 2011;70:500-507.

18. Salaffi F, Ciapetti A, Gasparini S, Carotti M, Filippucci E, Grassi W. A clinical prediction rule combining routine assessment and power Doppler ultrasonography for predicting progression to rheumatoid arthritis from early-onset undifferentiated arthritis. Clin Exp Rheumatol. 2010;28:686-694.

19. Scirè CA, Montecucco C, Codullo V, Epis O, Todoerti M, Caporali R. Ultrasonographic evaluation of joint involvement in early rheumatoid arthritis in clinical remission: power Doppler signal predicts short-term relapse. Rheumatology. 2009;48:1092-1097.

20. Brown AK, Conaghan PG, Karim Z, et al. An explanation for the apparent dissociation between clinical remission and continued structural deterioration in rheumatoid arthritis. Arthritis Rheum. 2008;58:2958-2967.

21. Filippucci E, Meenagh G, Epis O, et al. Ultrasound imaging for the rheumatologist XIII. New trends. Three-dimensional ultrasonography. Clin Exp Rheumatol. 2008;26:1-4.

22. Filippucci E, Meenagh G, Delle Sedie A, et al. Ultrasound imaging for the rheumatologist. XX. Sonographic assessment of hand and wrist joint involvement in rheumatoid arthritis: comparison between two- and three-dimensional ultrasonography. Clin Exp Rheumatol. 2009;27:197-200.

23. Strunk J, Lange U. Three-dimensional power Doppler sonographic visualization of synovial angiogenesis in rheumatoid arthritis. J Rheumatol. 2004;31:1004-1006.

24. Qvistgaard E, Røgind H, Torp-Pedersen S, Terslev L, DanneskioldSamsøe B, Bliddal H. Quantitative ultrasonography in rheumatoid arthritis: evaluation of inflammation by Doppler technique. Ann Rheum Dis. 2001;60:690-693.

25. Terslev L, Torp-Pedersen S, Qvistgaard E, von der Recke P, Bliddal H. Doppler ultrasound findings in healthy wrists and finger joints. Ann Rheum Dis. 2004;63:644-648.

26. Carotti M, Salaffi F, Morbiducci J, et al. Colour Doppler ultrasonography evaluation of vascularization in the wrist and finger joints in rheumatoid arthritis patients and healthy subjects. Eur J Radiol. 2012;81:1834-1838.

27. Terslev L, Torp-Pedersen S, Qvistgaard E, et al. Effects of treatment with etanercept (Enbrel, TNRF:Fc) on rheumatoid arthritis evaluated by Doppler ultrasonography. Ann Rheum Dis. 2003;62:178-181.

28. Hau M, Kneitz C, Tony HP, Keberle M, Jahns R, Jenett M. High resolution ultrasound detects a decrease in pannus vascularisation of small finger joints in patients with rheumatoid arthritis receiving treatment with soluble tumour necrosis factor alpha receptor (etanercept). Ann Rheum Dis. 2002;61:55-58.

29. Albrecht K, Grob K, Lange U, Müller-Ladner U, Strunk J. Reliability of different Doppler ultrasound quantification methods and devices in the assessment of therapeutic response in arthritis. Rheumatology. 2008;47:1521-1526.

30. Terslev L, Ellegaard K, Christensen R, et al. Head-to-head comparison of quantitative and semi-quantitative ultrasound scoring systems for rheumatoid arthritis: reliability, agreement and construct validity. Rheumatology. 2012;51:2034-2038.

31. Torp-Pedersen ST, Terslev L. Settings and artefacts relevant in colour/power Doppler ultrasound in rheumatology. Ann Rheum Dis. 2008;67:143-149.

32. Walther M, Harms H, Krenn V, Radke S, Faehndrich TP, Gohlke F. Correlation of power Doppler sonography with vascularity of the synovial tissue of the knee joint in patients with osteoarthritis and rheumatoid arthritis. Arthritis Rheum. 2001;44:331-338.

33. Saleem B, Brown AK, Keen H, et al. Should imaging be a component of rheumatoid arthritis remission criteria? A comparison between traditional and modified composite remission scores and imaging assessments. Ann Rheum Dis. 2011;70:792-798.

34. Teh J, Stevens K, Williamson L, Leung J, McNally EG. Power Doppler ultrasound of rheumatoid synovitis: quantification of therapeutic response. Br J Radiol. 2003;76:875-879.
35. Larché MJ, Seymour M, Lim A, et al. Quantitative power Doppler ultrasonography is a sensitive measure of metacarpophalangeal joint synovial vascularity in rheumatoid arthritis and declines significantly following a 2-week course of oral low-dose corticosteroids. J Rheumatol. 2010;37:2493-2501.

36. Ribbens C, André B, Marcelis S, et al. Rheumatoid hand joint synovitis: gray-scale and power Doppler US quantifications following anti-tumor necrosis factor-alpha treatment: pilot study. Radiology. 2003;229:562-569.

37. Filippucci E, Farina A, Carotti M, Salaffi F, Grassi W. Grey scale and power Doppler sonographic changes induced by intra-articular steroid injection treatment. Ann Rheum Dis. 2004;63:740-743.

38. Leen E, Horgan P. Ultrasound contrast agents for hepatic imaging with nonlinear modes. Curr Probl Diagn Radiol. 2003;32:66-87.

39. Wamser G, Bohndorf K, Vollert K, Bucklein W, Schalm J. Power Doppler sonography with and without echo-enhancing contrast agent and contrast enhanced MRI for the evaluation of rheumatoid arthritis of the shoulder joint: differentiation between synovitis and joint effusion. Skeletal Radiol. 2003;32:351-359.

40. Klauser A, Demharter J, De Marchi A, et al. The IACUS study group. Contrast enhanced gray-scale sonography in assessment of joint vascularity in rheumatoid arthritis: results from the IACUS study group. Euro Radiol. 2005;15:2404-2410.

41. Kleffel T, Demharter J, Wohlgemuth W, Schalm J, Bohndorf K, Kirchhof K. Comparison of contrast-enhanced low mechanical index (low MI) sonography and unenhanced B-mode sonography for the differentiation between synovitis and joint effusion in patients with rheumatoid arthritis. Rofo. 2005;177:835-841.

42. Magarelli N, Guglielmi G, Di Matteo L, Tartaro A, Mattei PA, Bonomo L. Diagnostic utility of an echo-contrast agent in patients with synovitis using power Doppler ultrasound: a preliminary study with comparison to contrast-enhanced MRI. Eur Radiol. 2001;11: 1039-1046.

43. Szkudlarek M, Court-Payen M, Strandberg C, Klarlund M, Klausen T, Ostergaard M. Contrast-enhanced power Doppler ultrasonography of the metacarpophalangeal joints in rheumatoid arthritis. Eur Radiol. 2003;13:163-168.

44. Wei K, Skyba DM, Firschke C, Jayaweera AR, Lindner JR, Kaul S. Interactions between microbubbles and ultrasound: in vitro and in vivo observations. J Am Coll Cardiol. 1997;29:1081-1088.

45. Correas JM, Bridal L, Lesavre A, Mejean A, Claudon M, Helenon O. Ultrasound contrast agents: properties, principles of action, tolerance, and artifacts. Eur Radiol. 2001;11:1316-1328.

46. Immer FF, Seiler AM, Aeschbacher BC, Mahler F, Saner H. Influence of the ultrasound contrast agent Levovist on human nailfold capillary microcirculation. Angiology. 2000;51:123-129.

47. Turetschek K, Huber S, Floyd E, et al. MR imaging characterization of microvessels in experimental breast tumors by using a particulate contrast agent with histopathologic correlation. Radiology. 2001;218: $562-569$.

48. Kim TJ, Moon WK, Cha JH, et al. VX2 carcinoma in rabbits after radiofrequency ablation: comparison of MR contrast agents for help in differentiating benign periablational enhancement from residual tumor. Radiology. 2005;234:423-430.

49. Turetschek K, Preda A, Novikov V, et al. Tumor microvascular changes in antiangiogenic treatment: assessment by magnetic resonance contrast media of different molecular weights. J Magn Reson Imaging. 2004;20: 138-144.

50. Fiocco U, Ferro F, Cozzi L, et al. Contrast medium in power Doppler ultrasound for assessment of synovial vascularity: comparison with arthroscopy. J Rheumatol. 2003;30:2170-2176.

51. Terslev L, Torp-Pedersen S, Bang N, Koenig MJ, Nielsen MB, Bliddal H. Doppler ultrasound findings in healthy wrists and finger joints before and after use of two different contrast agents. Ann Rheum Dis. 2005;64:824-827.

52. Lee V, Zayat A, Wakefield RJ. The effect of joint position on Doppler flow in finger synovitis. Ann Rheum Dis. 2009;68:603-604. 
Reports in Medical Imaging

\section{Publish your work in this journal}

Reports in Medical Imaging is an international, peer-reviewed, open access journal publishing original research, reports, reviews and commentaries on all areas of medical imaging. The manuscript management system is completely online and includes a very quick and fair peer-review system, which is all easy to use.

Submit your manuscript here: http://www.dovepress.com/reports-in-medical-imaging-journal 